\title{
Methylenetetrahydrofolate reductase polymorphism, diet, and breast cancer in Korean women
}

\author{
Sang-Ah Lee ${ }^{1}$, Daehee Kang ${ }^{1}$, Hisahide \\ $\mathrm{Nishio}{ }^{2}$, Myeong Jin Lee ${ }^{2}$, Dong-Hyun $\mathrm{Kim}^{3}$ \\ Wonshik $\mathrm{Han}^{5}$, Keun-Young Yoo ${ }^{1}$ \\ Sei-Hyun Ahn ${ }^{4}$, Kook-Jin Choe ${ }^{5}$ \\ Ari Hirvonen ${ }^{6}$, and Dong-Young Noh ${ }^{5,7}$ \\ ${ }^{1}$ Department of Preventive Medicine \\ College of Medicine, Seoul National University \\ 28 Yongon-dong, Chongno-gu, Seoul 110-799, Korea \\ ${ }^{2}$ Division of Public Health \\ Department of Environmental Health and Safety \\ Kobe University Graduate School of Medicine \\ 7-5-1 Kusunoki-cho, Chuo-gu, Kobe 650-0017, Japan \\ ${ }^{3}$ Department of Social and Preventive Medicine \\ College of Medicine, Hallym University \\ 1 Okchen-dong, Kangwan-do 200-702, Korea \\ ${ }^{4}$ Asan Medical Center \\ 338-1 Poongnap-dong, Songpa-gu, Seoul 138-736, Korea \\ ${ }^{5}$ Cancer Research Institute \\ College of Medicine, Seoul National University \\ 28 Yongon-dong, Chongno-gu, Seoul 110-799, Korea \\ ${ }^{6}$ Department of Industrial Hygiene and Toxicology \\ Finnish Institute of Occupational Health \\ Helsinki, Finland. \\ ${ }^{7}$ Corresponding author: Tel, 82-2-760-2921; \\ Fax, 82-2-766-3975; E-mail, dynoh@plaza.snu.ac.kr
}

Accepted 30 January 2004

Abbreviation: Methylenetetrahydrofolate reductase (MTHFR)

\begin{abstract}
s
To evaluate the interactive effect of methylenetetrahydrofolate reductase (MTHFR) genotype and dietary factors on the development of breast cancer, a hospital based case-control study was conducted in South Korean study population consisting of 189 histologically confirmed incident breast cancer cases and their 189 age-matched controls without present or previous history of cancer. A PCR-RFLP method was used for the genotyping of MTHFR (C677T) and statistical evaluations were performed by unconditional logistic regression analysis. Consumption of some dietary factors, such as green vegetables (OR $=0.3,95 \%$ $\mathrm{Cl}$ : $0.2-0.6)$, white vegetables $(O R=0.3,95 \% \mathrm{Cl}$ :
\end{abstract}

0.1-0.7) mushrooms (OR $=0.4,95 \% \quad \mathrm{Cl}: 0.3-0.7)$, and meats (OR $=1.7,95 \% \mathrm{Cl}: 1.1-2.8)$ significantly decreased or increased the risk of breast cancer. Although the breast cancer risk was 1.7 -fold $(95 \%$ Cl: 0.8-3.2) increased in women with MTHFR TT genotype, the association was not statistically significant. Women with MTHFR TT genotype and low green vegetable intake increased 5.6 -fold $195 \% \mathrm{Cl}$ : 1.2-26.3) risk of breast cancer compared to high green vegetable intake group containing MTHFR CC/CT genotype. However, the interaction was not significant ( $p$ for interaction $=0.96$ ). Our findings suggest that MTHFR polymorphism did not influence individual susceptibility to breast cancer. However MTHFR (C667T) genotype and green vegetable intakes appeared to have the interactive effect in breast cancer development.

Keywords: MTHFR; genetic polymorphism; green vegetable; breast cancer

\section{Introduction}

Methylenetetrahydrofolate reductase (MTHFR) acts at a critical metabolic juncture in the regulation of cellular methylation reaction by catalyzing the conversion of 5,10-methylenetetrahydrofolate to 5-methyltetrahydrofolate (Frosst P et al., 1995). A C677T base change in the MTHFR gene causes an alanine to valine substitution in the MTHFR protein, which is associated with reduced enzyme activity; individuals with the MTHFR TT and CT genotypes have only about $30 \%$ and $65 \%$, respectively, of the in vitro enzyme activity seen in those with the CC genotype (Frosst $P$, et al., 1995). Recently the MTHFR TT genotype was shown to be associated with halved level of DNA methylation compared with those with the CC genotype (Song KS et al., 2001; Frisco $S$ et al., 2002).

In a study involving a total of 88,818 women of the Nurses' Health Study, low levels of folate appeared as a risk factor for breast cancer if associated with high alcohol intake (Zhang $S$ et al., 1998). The possible protective role of dietary folate in breast carcinogenesis was supported by data from a population-based case-control study among 1321 cases and 1382 controls in urban Shanghai (Shrubsole MJ et al., 2001).

The recent evidence suggested that in addition to 
alcohol intake, the effect of folate in the breast cancer risk might be modulated by the MTHFR gene polymorphism (Gershoni-Baruch $\mathrm{R}$ et al., 2000). Only one previous association study (Campbell IG et al., 2002) consisting of 233 breast cancer cases and 335 controls suggests that the low activity MTHFR C667T genotype may increase the risk of early onset breast cancer in Caucasian women. We conducted such a study in a Korean population, to evaluate the potential association between MTHFR C667T polymorphism and breast cancer risk and additionally to evaluate the interactive effect of MTHFR genotype and dietary factors on the development of breast cancer.

\section{Materials and Methods}

\section{Study subjects}

All study subjects were recruited from March 1994 to July 1998 from three teaching hospitals located in Seoul, Korea (Seoul National University Hospital, Borame Hospital, and Asan Medical Center) under the approval of the Institutional Review Board of Seoul National University Hospital. The selection of study subjects was described elsewhere (Yim DS et al., 2001). Women with a first diagnosis of histophathologically confirmed, incident breast cancer and from whom a blood sample was available were selected as cases $(n=204)$, Control subjects $(n=332)$, comprising individuals with no present or previous history of breast cancer, were simultaneously recruited in the same hospitals. Women with amenorrhea, previous history of hysterectomy, oophorectomy, hormone replacement therapy, and hormone-related disease such as thyroid problem were excluded from both groups. According to the above criteria, 189 cases and 233 control subjects were eligible for the study. Each patient was the frequency matched to one control subject according to the following age groups: under 29, 30-34, 35-39, 40-54, 55-69, and over 70 years. Consequently, the final study population consisted of 189 cases and 189 control subjects. A hospital based case-control study was conducted in South Korean study population consisting of 189 histologically confirmed incident breast cancer cases and their 189 age-matched controls without present or previous history of cancer with a sufficient blood sample available were recruited in the same department in the hospital during the same period.

Informed consent was obtained from all participants at the time of blood withdrawal. Information on demographic characteristics, education, marital status, family history of breast cancer, reproductive and menstruation, life style habits (including smoking, alcohol consumption) was collected using a questionnaire administered by trained interviewers. Informa- tion on alcohol consumption was obtained by three questions: (1) how frequently do you drink alcohol (i.e. per week, month, or year); (2) how long have you been drinking; and (3) have you ever quit drinking? Dietary data were collected by intervieweradministered questionnaire, using the short foodfrequency questionnaire method, consistency of five food groups and three cooking methods (frying, broiling, and grilling). A five food groups (mushroom, meats, green vegetables, white vegetables, and fruits), suspected of being associated with breast cancer, were selected from previous published studies and asked the frequencies of consumption (every day, $3-4 /$ month, 3-4/week, almost never). Green vegetables included lettuce, green pepper, perilla leaves, carrot, and squash. White vegetables included radish, cabbage, and soybean sprout. Meats included beef, pork, and chicken. Subjects were asked about the average frequency of intake for a period of one year prior to the interview. The information of cooking methods was not used for the analysis because of the many missing values.

\section{Genotyping}

MTHFR genotypes were assayed by enzyme digestion of Hinf I after PCR amplified, which was modified by Frosst et al. (1995). Blood was collected in $10 \mathrm{ml}$ heparinized tubes and centrifuged at 3,000 rpm for $10 \mathrm{~min}$ at room temperature within $10 \mathrm{~h}$ of collection. Plasma, buffy coat, and red blood cells were separated and stored at $-70^{\circ} \mathrm{C}$. The buffy coat $(0.5-1$ $\mathrm{ml}$ ) was kept frozen until DNA extraction by an Applied QIAGEN extraction kit using protocols and reagents supplied. The extracted DNA was stored in $-20^{\circ} \mathrm{C}$ until genotypes were determined. Polymerase chain reaction (PCR) was done with a PCR thermal cycler (TP2000, Takara Biomedicals, Kyoto, Japan) in $30 \mu$ reactions, using $200 \mathrm{ng}$ of genomic DNA in 1 $\times$ Expand HF buffer (Boehringer Mannheim, Mannheim, Germany) with $1.5 \mathrm{mM} \mathrm{MgCl}, 250 \mu \mathrm{M}$ dNTPs, $0.5 \mu \mathrm{M}$ primers and $0.7 \mathrm{U}$ of Expand ${ }^{\mathrm{TM}}$ High Fidelity PCR System Enzyme Mix (Boehringer Mannheim, Germany). The sequences of the primers were: 5 '-T GAAGGAGAAGGTGTCTGCGGGA-3'and 5'-AGGACGGTG-CGGTGAGA-GTG-3' (reference). The conditions for PCR included an initial denaturation at $94^{\circ} \mathrm{C}$ for $3 \mathrm{~min}$, followed by 30 cycles of denaturation at $94^{\circ} \mathrm{C}$ for $1 \mathrm{~min}$, annealing at $55^{\circ} \mathrm{C}$ for $2 \mathrm{~min}$, extension at $72^{\circ} \mathrm{C}$ for $3 \mathrm{~min}$, and a final extension at $72^{\circ} \mathrm{C}$ for $7 \mathrm{~min}$. The amplified products were digested with Hinf I (New England Biolabs Inc.) at $37^{\circ} \mathrm{C}$ for $4 \mathrm{~h}$. The C-to-T transition creates a new Hinf I site. The digested products were electrophoresed in a $3 \%$ agarose gel. 


\section{Statistical analysis}

Odds ratios (ORs) and 95\% confidence intervals (Cls) were calculated by unconditional logistic regression model. The ORs were adjusted for age, education, $B M I$, and family history of breast cancer. The combined effect of MTHFR and diets were assessed by adding multiplicative interaction product in the final model. To increase the statistical power, the respective genotypes were divided into two groups in the statistical analyses. The product variable between genotypes of MTHFR and diet intake (genotypes of MTHFR $\times$ intake of diet) was added in the logistic model when evaluating the interactive effect of MTHFR genotype and diets on breast cancer risk. Diets containing higher folate and/or with stronger statistical significance were only evaluated for the interaction with the MTHFR genotype. All analyses were carried out with the SPSS (version 10.0) statistical software package.

\section{Result}

The distribution of known risk factors of breast cancer was compared in cases and controls (Table 1). These two groups differed statistically in education $(P=$ $0.01)$, marital status $(P=0.05)$, family history of breast cancer ( $\mathrm{OR}=3.1,95 \% \mathrm{Cl}: 1.1-8.6)$, and alcohol consumption (OR $=1.6,95 \% \mathrm{Cl}$ : $1.0-2.8)$.

Among dietary factors, green vegetables $(\mathrm{OR}=0.3$, $95 \% \mathrm{Cl}: 0.2-0.6)$, white vegetables $(\mathrm{OR}=0.3,95 \% \mathrm{Cl}$ : $0.1-0.7)$, and mushroom (OR $=0.4,95 \% \mathrm{Cl}: 0.3-0.7)$ decreased the risk of breast cancer, but the intake of meat increased the risk $(\mathrm{OR}=1.7,95 \% \mathrm{Cl}: 1.1-2.8)$ (Table 2).

The distribution of MTHFR genotypes in the study population is shown in Table 3. Of all cases, $34 \%$ had the CC genotype, $54.4 \%$ had the CT genotype and $11.6 \%$ had the TT genotype; the distribution among controls was $31.2,51.6$, and $17.2 \%$, respectively. However, no significant deviation was observed in the prevalence of MTHFR TT genotypes in the breast cancer cases compared to controls, neither in the total study group nor when stratified by menopause status (Table 3 ).

Although the breast cancer risk was 1.7 -fold (95\% $\mathrm{Cl}$ : 0.8-3.2) increased in women with MTHFR TT genotype, the association was not statistical significant. Women with MTHFR TT genotype and low green vegetable intake increased 5.6 -fold $(95 \% \mathrm{Cl}$ : 1.2-26.3) risk of breast cancer compared to high green vegetable intake group containing MTHFR CC/CT genotype (Table 4). Women with MTHFR TT genotype and low mushroom intake increased 4.4 -fold (1.8-11.1) risk of breast cancer compared to women with high mushroom intake containing MTHFR CC/
Table 1. Selected characteristics for matched breast cancer cases and controls.

\begin{tabular}{|c|c|c|c|}
\hline Characteristics & Cases $(\%)$ & Controls (\%) & OR $(95 \% \quad C I)$ \\
\hline \multicolumn{4}{|l|}{ Age } \\
\hline Under 29 & $1(0.5)$ & $1(0.5)$ & \\
\hline $30-34$ & $18(9.5)$ & $18(9.5)$ & \\
\hline $35-39$ & $28(14.8)$ & $28(14.8)$ & $1.00^{\mathrm{MH}}$ \\
\hline $40-54$ & $90(47.6)$ & $90(47.6)$ & \\
\hline $55-69$ & $42(22.2)$ & $42(22.2)$ & \\
\hline Over 70 & $10(5.3)$ & $10(5.3)$ & \\
\hline \multicolumn{4}{|c|}{ Education (year) } \\
\hline$<12$ & $135(71.4)$ & $145(86.3)$ & \\
\hline$\geq 12$ & $54(28.6)$ & $23(13.7)$ & $0.01^{\text {Chisq }}$ \\
\hline \multicolumn{4}{|l|}{ Marital status } \\
\hline Single & $11(5.8)$ & $3(1.6)$ & \\
\hline Married & $178(94.2)$ & $184(98.4)$ & $0.05^{\mathrm{FET}}$ \\
\hline \multicolumn{4}{|l|}{ Family history } \\
\hline No & 170 (89.9) & $181(95.8)$ & 1.0 \\
\hline Yes & $19(10.1)$ & $8(4.2)$ & $3.1(1.1-8.6)$ \\
\hline \multicolumn{4}{|c|}{ Alcohol drinking } \\
\hline$<1 /$ month & $137(72.5)$ & $157(83.1)$ & 1.0 \\
\hline$\geq 1 /$ month & $52(27.5)$ & $32(16.9)$ & $1.6(1.0-2.8)$ \\
\hline \multicolumn{4}{|c|}{ Smoking (cig./lifetime) } \\
\hline$<400$ & $179(94.7)$ & $116(92.1)$ & 1.0 \\
\hline$\geq 400$ & $10(5.3)$ & $10(7.9)$ & $0.8 \quad(0.32-2.16)$ \\
\hline
\end{tabular}

MH, Mentel-Hanenszel's chi-square test for trend; Chisq, chi-square test; FET, Fisher's exact test.

CT genotype (data not shown). However, the interaction was not significant $(p$ for interaction $=0.96$, for green vegetable; $p$ for interaction $=0.56$, for mushroom).

\section{Discussion}

In this study, there was no difference in breast cancer risk associated with MTHFR genotype. The allele frequencies in controls were in Hardy-Weinberg equilibrium and the frequency of the MTHFR TT homozygotes $(11.6 \%)$ was similar with that previously observed in Chinese (17.2\%) (Song C, et al., 2001), Japanese $(14.8 \%)$ (Matsuo $\mathrm{K}$ et al., 2001), and Caucasians (15\%) (Zhang $S$ et al., 1998).

The results of previous association studies of the MTHFR C667T polymorphism and breast cancer are inconsistent. Gershoni-Baruch et al. (2000) reported that the $677 T$ allele occurred significantly more frequently in the Jewish women diagnosed with bilateral breast cancer or combined breast and ovarian cancer. Sharp et al. (Sharp L et al., 2002), however, did not 
Table 2. ORs and $95 \% \mathrm{Cls}$ for association between selected types of food and breast cancer risk.

\begin{tabular}{|c|c|c|c|c|}
\hline Food group & Cases & Controls & $\mathrm{OR}^{*}(95 \% \quad \mathrm{Cl})$ & $P$ value \\
\hline \multicolumn{5}{|c|}{ Green vegetables } \\
\hline$<1 /$ wk & $67(35.8)$ & $32(16.9)$ & 1.0 & \\
\hline$\geq 1 / w k$ & $120(64.2)$ & $157(83.1)$ & $0.3(0.2-0.6)$ & $P<0.001$ \\
\hline \multicolumn{5}{|c|}{ White vegetables } \\
\hline$<1 /$ wk & $19(10.2)$ & $7(3.7)$ & 1.0 & \\
\hline$\geq 1 / w k$ & 168 ( 89.8) & $182(96.3)$ & $0.3(0.1-0.7)$ & $P=0.015$ \\
\hline \multicolumn{5}{|l|}{ Fruits } \\
\hline$<1 /$ wk & $33(17.6)$ & $31(16.8)$ & 1.0 & \\
\hline$\geq 1 / w k$ & $154(82.4)$ & $158(83.6)$ & $1.0(0.6-1.7)$ & $P=0.784$ \\
\hline \multicolumn{5}{|l|}{ Mushrooms } \\
\hline$<1 /$ wk & $129(69.0)$ & $93(49.2)$ & 1.0 & \\
\hline$\geq 1 / w k$ & $58(31.0)$ & $96(50.8)$ & $0.4(0.3-0.7)$ & $P<0.001$ \\
\hline \multicolumn{5}{|l|}{ Meats } \\
\hline$<1 /$ wk & $130(69.5)$ & $148(78.3)$ & 1.0 & \\
\hline$\geq 1 / w k$ & $57(30.5)$ & 41 ( 21.7) & $1.7(1.1-2.8)$ & $P=0.032$ \\
\hline Total & $187(100.0)$ & $189(100.0)$ & & \\
\hline
\end{tabular}

*adjusted for age, education, BMI, and family history of breast cancer.

Table 3. ORs and $95 \% \mathrm{Cls}$ for association between MTHFR genotypes and breast cancer.

\begin{tabular}{lrlrlll}
\hline Genotype & Cases & \multicolumn{1}{c}{ Controls } & OR* $^{*}(95 \% \mathrm{Cl})$ \\
\hline All & & & & & & \\
CC & 58 & $(31.2)$ & 50 & $(34.0)$ & 1.0 & \\
CT & 96 & $(51.6)$ & 80 & $(54.4)$ & 1.0 & $(0.6-1.7)$ \\
TT & 32 & $(17.2)$ & 17 & $(11.6)$ & 1.7 & $(0.8-3.4)$ \\
CC+CT & 154 & $(82.8)$ & 130 & $(88.4)$ & 1.0 & \\
TT & 32 & $(17.2)$ & 17 & $(11.6)$ & 1.7 & $(0.8-3.2)$ \\
Premenopausal & & & & & & \\
CC & 33 & $(29.5)$ & 24 & $(29.6)$ & 1.0 & \\
CT & 59 & $(52.7)$ & 46 & $(56.8)$ & 0.8 & $(0.4-1.7)$ \\
TT & 20 & $(17.9)$ & 11 & $(13.6)$ & 1.5 & $(0.7-3.8)$ \\
CC+CT & 92 & $(82.2)$ & 70 & $(86.4)$ & 1.0 & \\
TT & 20 & $(17.9)$ & 11 & $(13.6)$ & 1.7 & $(0.7-3.9)$ \\
Postmenopausal & & & & & & \\
CC & 25 & $(33.8)$ & 23 & $(39.0)$ & 1.0 & \\
CT & 37 & $(50.0)$ & 32 & $(54.2)$ & 1.1 & $(0.5-2.5)$ \\
TT & 12 & $(16.2)$ & 4 & $(6.8)$ & 2.6 & $(0.7-9.7)$ \\
CC +CT & 62 & $(83.8)$ & 55 & $(93.2)$ & 1.0 & \\
TT & 12 & $(16.2)$ & 4 & $(6.8)$ & 2.4 & $(0.7-8.4)$ \\
\hline
\end{tabular}

*adjusted for age, education, BMI, and family history of breast cancer.

observe any significant difference in the genotype distributions between 62 cases and 66 controls within a case-control study from a Scottish population, whe-
Table 4. The ORs* and $95 \% \mathrm{Cls}$ for MTHFR genotypes in relation to green vegetables intake in breast cancer development.

\begin{tabular}{ccc} 
MTHFR & Green vegetable intake \\
genotypes & $\begin{array}{c}\geq 1 / \text { week } \\
\text { (cases/controls) }\end{array}$ & $\begin{array}{c}<1 / \text { week } \\
\text { (cases/controls) }\end{array}$ \\
\hline CC+CT & 1 & $3.8(2.1-6.9)$ \\
& $(97 / 109)$ & $(57 / 19)$ \\
TT & $1.8(0.9-3.6)$ & $5.6(1.2-26.3)$ \\
& $(22 / 17)$ & $(10 / 2)$
\end{tabular}

*adjusted for age and family history of breast cancer, $p$ for interaction $=0.96$.

reas Campell et al. (2002), however, suggested a positive association between low MTHFR activity genotype and the risk of early onset breast cancer in Caucasian women. Inconsistencies from previous studies might be due to several factors including small sample sizes, subject selections, and interethnic difference in allele frequencies, and so on.

Consistent with our findings, majority of previous studies on the risk of breast cancer and dietary habits suggest a moderate protective effect for a high consumption of vegetables (Gandini $S$ et al., 2000). For fruit intake, however, study results were less clear. Fruits and vegetables are common sources of many candidate protective substances, including caroteno- 
ids, with and without vitamin A activity, and ascorbic acid. Caroteinoids and vitamin $C$ may protect against breast cancer due to their role in antioxidant defense. If the consumption pattern of fruits is more homogenous than vegetables, or vice versa, in any given population, and both groups are equally protective per amount consumed, then the food group with the wider range of exposure is more likely to yield a larger effect (Gandini S et al., 2000). However, the intake of meat increases the risk of breast cancer in this study. Recently, there has been interest in evaluating whether intakes of specific types of fat are associated with the risk of breast cancer. A pooled analysis of cohort studies (Smith-Warner SA et al., 2001) are suggestive of a weak positive association for substituting saturated fat consumption for carbohydrate consumption; however, substituting monounsaturated fat consumption for either saturated or polyunsaturated fat intakes was associated with a nonsignificantly lower breast cancer risk. In Korea, almost all the intake of saturated fatty acid comes from meat, especially beef, pork, or chicken.

Since folate levels were not analyzed in this study, we could not directly evaluate the interacting effect of folate and MTHFR on breast cancer risk. However, given that in a previous study on colon cancer, the beneficial effect of MTHFR mutant type on cancer risk was not observed among individuals with lower folate intake or higher alcohol consumption ( $\mathrm{Ma} \mathrm{J}$ et al., 1997), the present lack of significant interaction between the MTHFR genotype and folate intake on breast cancer risk could possibly be explained by the reportedly low average level of folate intake in Korean women (Lim HS et al., 2000).

In addition to not measuring folate levels in blood (plasma or RBC), this study had some other limitations like being a hospital-based study. However, the power of this study was $72 \%$ (one-side test of significance, $\alpha=0.05$ ) for detecting a modest OR of 1.7 for association between MTHFR TT genotype and breast cancer risk.

In conclusion, our results suggest that MTHFR (C677T) genotype has no significant modifying role in susceptibility to breast cancer in Korean population, but the MTHFR (C677T) polymorphism and some diet intakes appeared to have the association in breast cancer development. Further studies involving larger number of subjects are needed to confirm these preliminary observations.

\section{Acknowledgment}

This study was supported by grant (2003-022) from the Asan Institute for Life Sciences, Seoul, Korea.

\section{References}

Campbell IG, Baxter SW, Eccles DM, Choong DY. Methylenetetrahydrofolate reductase polymorphism and susceptibility to breast cancer. Breast Cancer Res 2002;4:R14

Friso S, Choi SW, Girelli D, Mason JB, Dolnikowski GG, Bagley PJ, Olivieri O, Jacques PF, Rosenberg IH, Corrocher $\mathrm{R}$, Selhub J. A common mutation in the 5,10-methylenetetrahydrofolate reductase gene affects genomic DNA methylation through an interaction with folate status. Proc Natl Acad Sci 2002;99:5606-11

Frosst $\mathrm{P}$, Blom HJ, Milos R, Goyette $\mathrm{P}$, Sheppard CA, Matthews RG, Boers GJ, den Heijer M, Kluijtmans LA, van den Heuvel LP, Rozen R. A candidate genetic risk factor for vascular disease: a common mutation in methylenetetrahydrofolate reductase. Na Genet 1995;10:111-3

Gandini S, Merzenich H, Robertson C, Boyle P. Metaanalysis of studies on breast cancer risk and diet: the role of fruit and vegetable consumption and the intake of associated micronutrients. European J Cancer 2000;36:636-46

Gershoni-Baruch R, Dagan E, Israeli D, Kasinetz L, Kadouri $\mathrm{E}$, Friedman $\mathrm{E}$. Association of the C677T polymorphism in the MTHFR gene with breast and/or ovarian cancer risk in Jewish women. Eur J Cancer 2000;36:2313-6

Lim HS, Jin HO, Lee JA. Dietary intakes and status of folate in Korean women of child-bearing potential. Korean $\mathrm{J}$ Nutr 2000;33:296-303

Ma J, Stampfer MJ, Giovannucci E, Artigas C, Hunter DJ, Fuchs C, Willet WC, Selhub J, Hennekens CH, Rozen R. Methylenetetrahydrofolate reductase polymorphism, dietary interaction, and risk of colorectal cancer. Cancer Res 1997; 57:1098-102

Matsuo K, Suzuki R, Hamajima N, Ogure M, Kagami Y, Taji H, Kondoh E, Maeda S, Asakura S, Kaba S, Nakamura S, Seto M, Morishima Y, Yajima K. Association between polymorphisms of folate- and methionine-metabolizing enzyme and susceptibility to malignant lymphoma. Blood 2001;97: 3205-9

Sharp L, Little J, Schofield AC, Pavlidou E, Cotton SC, Miedzybrodzka Z, Baird JO, Haites NE, Heys SD, Grubb DA. Folate and breast cancer: the role of polymorphisms in methylenetetrahydrofolate reductase (MTHFR). Cancer Letter 2002;181;65-71

Shrubsole MJ, Jin F, Dai Q, Shu XO, Potter JD, Hebert JR, Gao YT, Zheng W. Dietary folate intake and breast cancer risk: results from the Shanghai breast cancer study. Cancer Res 2001;61:7136-41

Smith-Warner SA, Spiegelman D, Adami HO, Beeson WL, Van Den Brandt PA, Folsom AR, Fraser GE, Freudenheim JL, Goldbohm RA, Graham S, Kushi LH, Miller AB, Rohan TE, Speizer FE, Toniolo P, Willett WC, Wolk A, ZeleniuchJacquotte A, Hunter DJ. Type of dietary fat and breast cancer: a pooled analysis of cohort studies. Int $\mathrm{J}$ Cancer 2001;92:767-74

Song C, Xing D, Tan W, Wei Q, Lin D. Methylenetetrahydrofolate reductase polymorphisms increase risk of esophageal squamous cell carcinoma in a Chinese population. Cancer Res 2001;61:3272-5 
Song KS, Song JW, Choi JR, Kim HK, Shin JS, Kim JH. Homozygous VN (677C to T) and D/D (2756G to $A$ ) variants in the Methylenetetrahydrofolate and methionine synthase genes in a case of hyperhomocystenemia with stroke at young age. Exp Mol Med 2001;33:106-9

Yim DS, Park SK, Yoo KY, Yoon KS, Chung HH, Kang HJ, Ahn SH, Noh DY, Choe KJ, Jang IJ, Shin SG, Hirvonen
A, Kang D. Relationship between the $V a l^{158}$ Met polymorphism of catecol O-methyl transfrease and breast cancer. Pharmacogenetics 2001;11:279-86

Zhang S, Hunter DJ, Hankinson SE, Giovannucci EL, Rosner BA, Coditz GA, Speizer FE, Willett WC. A prospective study of folate intake and risk of breast cancer. JAMA 1998;281: 1632-7 